\title{
Palliative Care and the Ethics of Hospitality
}

\author{
Nishant A Irudayadason* \\ Professor of Philosophy and Ethics, Jnana-Deepa Vidyapeeth, Pontifical Institute of Philosophy and Religions, Ramwadi, \\ Nagar Road, Pune- 411014, Maharashtra, India.
}

Received: March 16, 2018; Accepted: March 27, 2018; Published: April 03, 2018

*Corresponding author: Nishant A Irudayadason, Professor of Philosophy and Ethics, Jnana-Deepa Vidyapeeth, Pontifical Institute of Philosophy and Religions, Ramwadi, Nagar Road, Pune - 411014, Maharashtra, India, Tel: +91902876125; Email: nishant@jdv.edu.in

\section{Introduction}

Death is inevitable. We may agree with some philosophers for whom "as soon as a human being is born, he is old enough to die right away."[1] The Greeks understood mortality as the condition of human beings who can have the idea of immortality without having the actual experience of it. We have accepted our mortal condition as our destiny, but at the same time we want to embrace death on own terms. The contradiction presented in the binary opposition between euthanasia and palliative care confirms this. In this binary, the first adheres to the position that time prolonged for a terminal patient is useless, while the second holds that a patient waiting at the end of time, however prolonged it may be, is meaningful. The ambivalent response of "doing the best "in the face of death-which can mean both euthanasia and palliative care-makes us wonder what it means to die. Dying cannot be viewed merely as a problem of technological advancements related to the medicalization (Medicalization is the process by which human conditions and problems come to be defined and treated as medical conditions, and thus become the subject of medical study, diagnosis, prevention, or treatment) of death. If the medically defined health and well-being become the new yardstick to measure happiness, what place does the reality of death have in life? Instead of patiently awaiting deathliving is learning to die-do we attempt to take recourse to medical technology to decide the hour of death under the pretext of ending life in a dignified manner? Amidst these intriguing questions, in this paper we attempt to explore if palliative care helps us to invent an ethic of radical hospitality to the patients at the end of life.

\section{Knowing Ourselves as Dying}

The gap between knowing ourselves as mortal beings without the possibility of knowing the day and hour of death and knowing ourselves as dying on a specific day has blurred. Medical science and technology have increased our knowledge and our abilities to fight death. Except in the case of fatal accidents, the anticipation of the end of life becomes a fact of diagnosis. Under normal circumstances, the day of a patient's death is predictable. Contemporary medicine, by increasing our knowledge of death, has also increased the scope of our responsibility without being able to define the right thing to be done. The debate between euthanasia and palliative care is based on this ambiguity. The extension of our knowledge in medical science is not the necessarily synonymous to the deepening of our moral sense. If Pascal noted that "Being unable to cure death, wretchedness and ignorance, men have decided, in order to be happy, not to think about such things," we can say that human persons who can "predict death" are unhappy for having to think about it. [2] Our new knowledge in medical science leads to the exercise of an initiative on what was understood as the very moment of disengagement from any initiative, namely death. The haunting question to the medical establishment is "what to do when there is nothing left to do for cure?"

From the patient's point of view, Jérôme Pore observes that the gap is widening between a medical knowledge driven by the certainty of being able to predict illness and death, and the existence of the patient without the possibility of cure. Should we not be ignorant about certain things for our existence to be tolerable? When hospitals begin to predict death through a cold objective accepting the idea of death becomes an existential issue with unpredictable subjective repercussions! The consequence of the shift from knowing ourselves as mortal and knowing ourselves as dying is not necessarily pleasant. [3]

The very expression of "I die" in the first person is impossible because if the sentence is true then I cannot say what I say, or the sentence cannot be true. I cannot be a contemporary of my own death. But this has now changed since medicine makes the idea of the end of life foreseeable and predictable under the effect of its own technological limitation. The creation of intensive care medicine related to the inability to continue to care further not only exposes our mortal condition but also makes it come alive. The living experience of what philosophers called finitude is right before the patient who is not dead yet but dying.

\section{The Nuanced Idea of Palliative Care}

In the broad sense, all care is palliative in so far as our care can only temporarily mitigate what alters our condition. All care is palliative because we do not cure death. Thus, the distinction between curative care of medical intervention against a disease and palliative care when no treatment can reverse a lifethreatening illness is hardly relevant. All care is palliative. They palliate. 


\section{Subjectivity and Death}

Palliative care manifests some salient features in its approach to death, of which the most important one is the recognition of the dying person as a singular subject with his or her own individuality. Affirmation of individuality implies that society is no longer more important than the individual in the society and these results in a fundamental change in our approach to death. Society cannot live the experience of the dying individual but can accompany him or her. Tradition conveyed the idea of death as a social event. The imagery of the funeral vigil, burial in great pomp and the farewell ceremony manifested the encompassing and structuring character of society and religion. Preparation for death is ritualized in social conventions.

When the dying individual takes precedence over social conventions, death is faced in its singularity, giving rise to the invention of personalized gestures through the psychological intensification of a person's relation to himself or herself. While confronting death, the dying person no longer relies on social institutions but on his or her own psyche. In palliative care, accompanying the dying person involves finding coherence in the demand of the dying individual and not in the social convention. The consequence of individuality in the end of life is not isolation, but the accompaniment of the dying through the network of family, chaplains and caregivers.

The subjective experience of death leads to a disenchantment with the world. The psychological importance of serenity becomes important and the exercise of preparation for death assumes psychological character. The psychologist's place in palliative care signals a tendency in favour of the therapeutic serenity of the dying person. As for the "spiritual needs" of the dying, attempts are made to rediscover the meaning of dying not through traditional discourses but through the psychological discourses. The end-of-life time must be beneficial, at least psychologically.

\section{Technological Rationality}

Unfortunately, the language of technology generates a technological approach to relationship. Strangely, in medical establishments, the language of the end of life is shaped by scientific and technological rationality. We find ourselves in what Jacques Ellul called the "Technological system."[4] Technology has become autonomous to produce its own values: efficient, cost-effective and useful. It inaugurates an effective pervading utilitarianism: the triumph of utility is measured in terms of efficiency. From this perspective, accompaniment of the person at the end of life is paradoxically at the service of this logic of efficiency.

The technological system has led to make utilitarianism an invasive norm for the accompaniment at the end of life. The term utilitarian involves the use of technological devices to increase performance and efficiency. This can potentially render service to the dying person as there is a utilitarian dimension of the analgesic in the reduction of pain. Thus, the term useful has come to mean the use of technological devices to achieve a given purpose effectively and proved to be so. It is important to make a distinction between the terms "useful" and "utility." The term useful is ethically neutral, in the sense that a gun like an analgesic is useful. The value of what is useful therefore lies in its horizon of application. The term utility is value laden because it offers a criterion for morality according to the utilitarian tradition which claims that the morality of an action lies in the fact that it contributes to the happiness of the greatest number.

The dominant scientific and technological rationality reduces the meaning of the term useful to utility making what is costeffective as worth. The principle of utility is used in the hospital manifested in the race for possession of the better technologies and better health care providers according to the criteria of the technological expertise. Those who are not able to produce quantifiable performance in health care sectors, even though they may be sensitive enough to understand intuitively the needs of the patients and cater to them, are considered useless.

With the dawn of the utilitarian idea, the short duration of death has become useless. This aspect is reinforced by an improvement of resuscitation techniques, prolonging the duration of death. The biomedical technology blurs the anthropological boundaries between living and existing, which we have so far believed to be indisputable. A pure biological approach adopted by medical science creates strange situations. A person is medically healthy but biologically sick for predictive medicine. A person can be clinically dead but still alive. A person is kept alive through the technological innovation of artificial respiration, but we not know any more if he or she has a life. In short, the individual at the end of life must assume the fact of knowing if he or she is still living since technology does not assure it.

\section{From Medical Treatment to Palliative Care}

Palliative care is a turning point in the history of medical institutions. It makes a shift from the assurance of medical interventions to the acceptance of its powerlessness. It challenges the biological and technological approaches of medical care. Biomedicine is built on the constituent principle of "everything is possible," on the premise of a potential unlimited means of treatment, making the inevitable fact of death into an incurable disease. Due to the increased technological presence in the field of medical science, from the art of medical care involving both risk and trust we have moved to the technology of medical care involving certitude and precision. Death then becomes our failure if not dishonour. Ricoeur's understanding of medical care is noteworthy in this context:

It is a pact between two people: the patient who is suffering asks for help, and the doctor who knows what to do and offers treatment. A pact is formed based upon trust: the patient believes that the doctor can and wants to treat, if not to cure him or her; and the doctor counts upon the patient to behave as the agent of his own treatment. The act of forming the alliance is recorded in the prescription. I will show later its equivalent in the act of judgment in a court of law. I cannot emphasize enough the unique character of the treatment pact made by two particular individuals; the doctor, the patient, and the prescription that initiates a singular 
experience regarding the treatment of this patient in connection with this doctor.[5]

Another major shift made by palliative care is that it moves away from the effectiveness of medical practice that requires analysis of organs needing treatment to palliative synthesis of focusing on the human subject under care as a whole. Thanks to the biomedical approach, the human person has lost his or her status as a subject but made into an object to be known though the interposition of chemical formulas. Palliative care contributes to find the subject of care. The powerlessness of technology makes us to discover the fragility of the human person in need of care.

Finally, palliative care makes possible the passage from limiting the scope of medicine within the field of science to acknowledging it as a vision of life. The contemporary medical industry formulates a new categorical imperative: "succeed life dietetically, succeed death medically!" On the contrary, Palliative care has become a paradigm for considering the totality of human existence. This is significantly different from the contemporary technological approach to medical treatment.

\section{From Metaphysics of Death to Technology of Death}

For a long time, death is accepted as a fact of nature. Death is natural, so dying is normal. To die of natural causes was the figure of good death. Life in the metaphysical sense was associated with the living persons. This connection enveloped the discourse on the living persons within a vision of the world, a web of meaning and a system of metaphysics. This is no longer the case for contemporary technological medical practice that dissociates life from living persons. As suggested by the biologist François Jacob "we do not study life in laboratories." Life is disenchanted and biologized. Similarly, medicine evolved into biomedicine does not consider life but focuses on the living persons exclusively in the biological sense of the term. However, this disconnection generates a value judgment on the end of life as worthy or unworthy based on a life quality of the living person only in terms of biological norms thus leaving no scope for moral norms rooted in the metaphysics of life.

Similarly, the metaphysics of death has given way to the technology of death. By its close connection to the development of a technological culture, medical practices have not escaped the language of efficiency in describing death and the end of life. It is no longer the presence of a religious minister that sanctifies death, but of the doctor who qualifies it according to technological criteria. The criteria of utility and the efficiency deny value to what is not technologically qualified. If humanity resides in technological activities, in the prowess to make the impossible possible, then what is useless is not worthy. If utility is the positive mark of our power to act, the powerlessness of suffering is an undignified sign of social uselessness. Within this logic, what is good is no longer life, but death because we can no longer have self-esteem when dependence overwhelms our capacity for initiative.

From the perspective of medical practice, the end of life has become an object of technological control over undignified life of a person without medical success for cure. Strangely indignity is associated with the patient for whom nothing can be done medically to cure him and not with the medical treatment that does not help the patient to fulfil his dream of living. Unfortunately, the dominance of technological power still operates at the end of life. The medical cessation of acute care at the end of life is not neutral or amoral but involves an ethical choice. The meaning of the famous phrase "do what is best" is very diverse. It can either mean to choose the hour of the death to program it in a final mastery or to admit the limitations of the technology in the recognition of the ambiguity in the choice of choosing death over life.

\section{From Hospitalization to Hospitality}

Palliative care offers a chance for the final confrontation with the experience of evil. Leibniz made a distinction among physical, moral and metaphysical evil. If bodily pain means physical evil instead of symptom for a disease or condition for cure there is better possibility for active care. If the loss of selfesteem and dependency is taken as moral evil, palliative care, by emphasizing the importance of psychological support and companionship between caregivers and patients, can address it. The metaphysical evil that challenges the very meaning and purpose of existence can be addressed by offering hope to the patient through religious discourses and spiritual practices. It can also be addressed by palliative care through the ethics of hospitality tothe absolute strangeness of the end of life which makes the contours of elementary humanity.

The term hospitality is derived from the Latin hostis that carries the ambiguity attached to the host who is also a stranger. The host in danger can also be dangerous. The language of medical institutions does not acknowledge the equivocation between hospitality and hostility. We thus pass from the notion of hospital as a place of welcoming the wounded and the physically weak, to the concept of hospice for destitute considered dangerous, finally to the idea of the hospital as a place where powerlessness and fragility are rejected as hostile. Hostilities against diseases are declared in the therapeutic fight. Palliative care regains the hospitality dimension associated with hospital activities to the point of welcoming the fragile and dependent members of the society. The ethics of hospitality in palliative care tries to invent a language of benevolent hospitality to the fragile persons at the end of life against the norms of technological perform ativity and efficiency.

Thinking of hospitality as an ethical duty in contemporary medical institutions within the logic of technological efficiency is not a value any more. Contrary to this, by giving up the constraints placed on us by medical technology, palliative care embodies hospitality concretized in the relationship between the caregiver and the dying patient. This does not mean that we must condemn the medical science and the valuable knowledge it provides for an effective treatment of a patient. In fact, the resuscitation technology has made considerable progress. But a technological performance is not in itself a progress unless it is accompanied by palliative care, because the limitations of technology make us 
aware of the need for caring the dying person in a humble gesture of recognizing the impossibility of cure.

\section{Conclusion}

In palliative care, the accompanying period at the end of time is placed under the gaze of life, not of death. This period of accompaniment at the end of life is constituted by patience. The patient is not only a person who experiences suffering but also someone who keeps patience. In a mere technological approach, the value of time is determined by the number of activities done within the stipulated time. Unproductive time is considered a loss; every minute matters for the dying person as any moment can be fatal. This does not mean that patience can be considered meaningless even if it produces nothing apparently. In the patient waiting of embracing death, time is no longer an obstacle but an opportunity for the dying subject to be fully available to be at peace with his or her own self. The patient waiting at the end of time is not merely languishing in obscurity, but an experience of life lived through a meaningful quality time.
Accompanying a dying person at the end of life is the final utmost care that we can offer to the vulnerable humanity. In the rhetoric of fight that makes cure a victory in the battlefield of the sick body, palliative care offers hospitality for the dying other for whom, according to Levin as, we become hostage. [6]

\section{References}

1. Martin Heidegger. Being and Time: A translation of Sein und Zeit. Dennis J. Schmidth. New York: SUNY press, Albany; 1996.

2. Blaise Pascal. Pensées. Chapter VIII: Diversion 36. U. S. A: E. P. Dutton \& Co. ;2006.

3. See Jérôme Porée, "La philosophie à l'épreuve du mal. Pour une phénoménologie de la souffrance," Revue Philosophique de la France Et de l'Etranger. France: University Presses of France; 1996.

4. James Ellul. The Technological System. London: Continuum Press; 1980.

5. Paul Ricoeur. The Just and Medical Ethics in D.C. Thomasma, D.N. Weisstub and C. Harvey. Personhood and Health Care. Dordrecht: Kluwer Academy Publishers; 2001.

6. Martin Jay. Hostage Philosophy: Levinas's Ethical Thought. Tikkun; 31(3): 71-72; 2016. 